This article is (c) Emerald Group Publishing and permission has been granted for this version to appear here https://opus.lib.uts.edu.au/handle/10453/122825. Emerald does not grant permission for this article to be further copied/distributed or hosted elsewhere without the express permission from Emerald Group Publishing Limited. 


\title{
AN ENTERPRISING PHOENIX: MATERIALITY, AFFECT AND LEARNING
}

Keywords: organizational change, affect, learning, materiality

\author{
ABSTRACT \\ Purpose \\ The purpose of this paper is to explore how workers experience planned and unplanned \\ change(s), how the effects of change endure in organizations and the entanglement \\ (Gherardi 2015) of materiality, affect and learning
}

\section{Design}

Research design is ethnographic in nature and draws from 30 semi-structured interviews of workers in an Australian organisation. Interviews were designed to elicit narrative accounts (stories) of challenges and change faced by the workers. Desktop research of organizational documents and material artefacts complemented interview data. Analysis is informed by socio-material understandings, and in particular the ideas of materiality, affect and learning.

\section{Findings}

Change, in the form of a fire, triggered spontaneous and surprisingly positive affectual and organizational outcomes that exceeded earlier attempts at restructuring work. In the wake of the material tragedy of the fire in one organization, what emerged was a shift in the workers and the practices of the organization. Their accounts emphasized challenges, excitement and renewal, which prompt reconsideration of learning at work. In particular, the entanglement of affect, materiality and learning in times of change.

\section{Value}

Much workplace learning research identifies change as conducive to learning. This paper builds on this research by providing new understandings of, and insights into, the enduring effects of change. 


\section{INTRODUCTION}

Three decades of concentrated effort in workplace learning research has progressed the general field substantially. Over this period understandings of workplace learning have become available through developments in conceptual ideas used to frame them. Hager (2011) traces three main categories of theoretical development. First are theories drawing mainly on psychological ideas that are well represented in earlier accounts of workplace learning (e.g. behaviourism). Second are socio-material theories, which are attentive to social context and generally reject the individual focus of the first group (e.g. Billett 2004; Lave \& Wenger 1991). Finally, postmodern ideas, that among other things, more or less see learning as emergent, give prominence to the sociomaterial, and are attentive to the relationship between learning and practices (Fenwick 2016; Gherardi, Nicolini \& Odella 1998; Hager 2014). While not necessarily accepting the nomenclature of Hager's third category (Hager himself anticipated this rejection), we agree with its general tenets and locate this paper in this research space.

Here we are interested in the 'entanglement' of materiality, affect and learning (Gherardi 2015) in stories of change. Change has been featured in much workplace learning literature. Whether it is explicitly named or implied, large-scale or minor change(s) in day to day work has come to been seen as having an impact on learning for workers. In a recent review of organizational change literature Al-Haddad \& Kotnour (2015) maintain that the notion of a planned approach to organizational change is strong. Similarly Kezar (2001) found that the majority of organizational change research reflected a teleological perspective. This suggests that organizations are understood as purposeful entities, where change is inherently logical and follows a linear path. The underlying assumption of teleological organizational change models reflects change as a means for organizations to achieve a desired end state or goal. These models of change depict change as planned directed from the top and, depending on the particular model being adopted, having employees involved to varying degrees in the implementation of the change. The degree of change required is assessed based on an organization's state in relation to a desired end state or goal.

In contrast to these views of change, we propose a practice perspective that draws on the work of those like Schatzki and Gherardi. Firstly, Schatzki (2010a) conceptualises practices 
as the underpinning structure of social life as it plays out in sites. Organizations are particular kinds of social sites comprising 'practices and material arrangement bundles' (p. 72). Practices are understood as prevailing, i.e. they continue in stable ways, but at the same time they are also open-ended. It is the open-endedness of a practice that implicates learning. This is because in the enactment of a practice, open-endedness means there is always the potetential to do something differently: i.e. to change. Gherardi (2008a), too, maintains that people draw on a multiplicity of learnings gained through participation in practices that are ever open to change. Like those before us, we propose that learning is enmeshed in the carrying out of everyday work practices - practices that are situated, emergent and subject to site-specific organizational changes (ANON 2009).

While change in practices may be the result of a planned organizational intervention, practice changes can also occur as a consequence of unplanned material events. In these cases new practices emerge, affecting what workers do at the local level (Schatzki, 2002). As educational researchers, our main interest has emerged through our analysis of the organizational stories constructed by workers around the precipitating changes brought about by a fire amid a deliberate organizational change strategy driven by neo-liberal reforms of local government (ANON 2009). Thus, this paper is set against growing interest in research into organizations as unique sites of learning, of change, work practices and materialities (Czarniawska 2004; Gherardi 2008b; ANON 2013; Schatzki 2010a).

The paper draws on accounts of change as told by workers in one particular organization. While the workers' stories were elicited as part of a research project undertaken in the early 2010s, they represent two major organizational changes (a major restructure and a fire) that occurred in the organization over the previous three decades. Not only did these changes dramatically reshape the organization at the time of their occurrence, but their effects also endure as the contemporary organization faces yet another major change to be 'fit for the

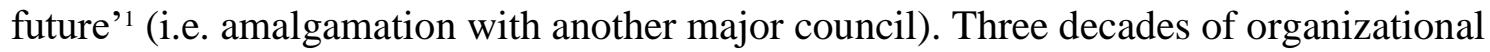

\footnotetext{
${ }^{1}$ Fit for the Future. A Blueprint for the future of Local Government http://www.fitforthefuture.nsw.gov.au/sites/fftf/files/Fit-for-the-Future-A-Blueprint-for-the-future-of-LocalGovernment.pdf
} 
change stories in one organization provide us with a unique opportunity to illustrate temporal and other dimensions of change that bring the past into the present and even into the future. In doing this, the continuum of co-existence and experience of the workers is revealed as they are connected to the social dimensions and materiality of the site.

The paper begins by providing details of the study including the overarching research project approach. It then introduces the specific 'site', a Local Government Organization in Sydney, Australia: Phoenix City Council (a pseudonym), hereafter referred to as PCC, or The Council. Methods of data collection within the site are then detailed followed by a description of emergent conceptual framings of the data. This multiple conceptual framing enables the change stories from The Council that follow. The stories of PCC, as told by its workers, provide a macro cultural context involving major organizational change and are stories which include new ways of doing, saying, seeing, relating (and experiencing) precipitated by change. This first framing includes narratives related by individual workers, stories that resonate with, and become organizational stories, intertwined in the organizational practice memory (Schatzki 2006). Our emerging conceptualisations then take the later part of the paper to a second framing that sees the fire as a material event that not only reconnects past, present, and new materialities, but also sets a radical process of change in train. Affectual dimensions - the excitement, challenge and renewal - of work perpetuate these changes. In this analysis we consider the entanglement (Gherardi 2015) of materiality, affect and learning, and examine how individually and collectively workers responded impulsively in ways that facilitated change and learning.

\section{THE RESEARCH}

Our interest in organizational change events and practices is related to a three-year Australian Research Council (ARC) $)^{2}$ project. The research focus is on work practices, in particular, on organizational practices that facilitate learning yet are independent of formal education and training programs. This involved developing and investigating detailed

\footnotetext{
2 This data was kindly supplied from and collected for research that was funded by the Australian Research Council (ARC) Discovery Grant DP0888615 entitled 'Beyond Training and Learning: Integrated Development Practices'.
} 
accounts of specific learning practices and their effects on individual workers and on the organizations selected.

\section{Research site}

The research involved four organizational research sites: a community college, a winery, a public utility and a Local Council. In this paper re refer only to the later research site, the local council. PPC is a large local Council in the Sydney metropolitan area employing approximately 600 people and managing around $\$ 900$ million worth of assets. Local Councils represent the third layer of government in Australia and they are responsible for service provision and governance at a local community level. The Council provides a vast number of services to its local community including the provision of library and community services, road maintenance, waste collection, building development assessments, parks and community centres as well as health and regulatory services. PCC's structure was hierarchical, with the General Manager overseeing all operations and four Group Managers responsible for the day to day running of three specific divisions of PCC's operations.

\section{Approach and methods}

The research initially takes a narrative approach and in using this approach we take as given that 'people tell stories to entertain, to teach and to learn, to ask for an interpretation and to give one' (Czarniawska 2004, p. 10). Our concern here is not in the realms of epistemology, following Czarniawska, i.e. we are not interested in asking if these narratives are 'real' or not. Rather, we are interested in how the narratives of workers illuminate the complexities and relationships of practice change, as well as how they provide insights into learning (at) work.

Our narrative approach meant that interviews constitute the primary data method, although complemented by other methods including unstructured observations, document and artefact analysis. The funded research project was advertised in The Council and volunteers were called for throughout the organization with support of senior management. In total, we interviewed 30 PCC workers from various works groups and levels across the organization. They included senior managers, field workers (e.g. parking officers, rangers, dog catchers) 
as well as engineers, planners and librarians. The interviewees' length of employment at the Council ranged from 3 months to over 30 years.

In keeping with our approach we used open-ended interview questions designed to elicit narrative accounts of workers going about their work. Interviews were approximately one hour in duration and were held in offices and meeting rooms (for indoor workers) and onsite or in coffee shops (for outdoor workers). All interviews were recorded and then transcribed.

In our initial analysis, we were interested in the stories (narratives) of work that featured learning and change, as well as descriptions of common practices that were part of everyday work. Like the workers we report on, in giving our interpretation, we ourselves remained open to emergent and new possibilities of our learning about the organizations. As analysis progressed we noticed similarities emerging in the ways workers talked about their experiences of change. This led to a second layer of analysis where practice conceptualisations (Gherardi 2017) invited us to explore how these stories revealed affective dimensions of organizational change, and significantly, how these implicated learning.

\section{STORIES OF CHANGE AT PCC}

Over the past three decades PCC has faced what might be described as three 'happenings' of change. The enactment of the 1993 Local Government Act, and the implementation of a National Competition Policy in the State of New South Wales in Australia, marked an important turning point for PCC. The Council was being positioned (and began positioning itself) within the discourses and practices of new public management (Brunsson \& SahlinAndersson 2000).

PCC began its own restructuring processes that focussed on simultaneously improving its customer focus and increasing competitiveness in providing services in an open and contestable market through the 'purchaser-provider split' (ANON 2011). At the core of the reform was a push towards efficiency, service delivery and the management of resources. The introduction of principles and practices of business competition meant a major shift in the traditional approach to service delivery: a traditional approach that was described by 
one worker as resembling 'a sheltered workshop', a metaphor that conjures up images of employment protection and perhaps repetition and lack of change.

Two years after the PCC restructure a major event occurred: a fire. In 1997, as result of a 'wayward spark' from a grinding tool used during air conditioning work being undertaken in the roof space of PCC's administration building (the location of The Council), it burned to the ground. As researchers, we were struck by the extent to which this material event had entered the discourse of all workers in our engagement with them. Without exception, every worker we interviewed referred to the fire in his or her interview. Most spoke of how, despite the disaster, The Council was operational within a remarkably short period of time (hours) after the fire:

Like the same day we burnt down, we had customer service staff on the ground, in the park, dealing with customers, because life went on. So, there was this real feeling of achievement that we'd actually gone through another major crisis like the restructure, and it was the biggest buzz. If you can imagine, we had to find houses, housing for everyone, we had to figure out people's jobs - so, there was a lot of absolutely urgent activity, as well as everything that was happening.

This 'fire story' was told not only by workers who were actually there at the time, but also by workers who had joined the organization since. These narratives it seems had become part of the 'affective' induction of new workers into PCC. The fire had become an integral part of the 'organizational practice memory' (Schatzki 2006) of PCC. The most recently employed worker we spoke with had been employed at PCC for three months, yet she also recounted the 'fire story':

So the fire is something that you hear - what I feel is the fire is something that's actually given [The Council] an identity I mean in some ways it's a story that is just about us and it happened to us and the fantastic stories that came out of it - like all the pieces of The Council were operating within [a] short period of time - in all different places - those types of stories - people become - people talk about them with wide eyes and excitement. 
The fire and its aftermath in the PCC were sustained - not just in changed work practices and the discourse - but in the longevity of the artefactual persistence of the workers' practices in relation to it. What struck us was the materialised memory of the fire, the importance of which was sustained through fire-related artefacts that were repeatedly brought out to illustrate the fire story. For example, during interviews we were (proudly) shown scorched and water stained documents, and we were taken to the General Manager's office where a framed and charcoaled mayoral chain hung conspicuously on a wall (shown below in Figure 1).

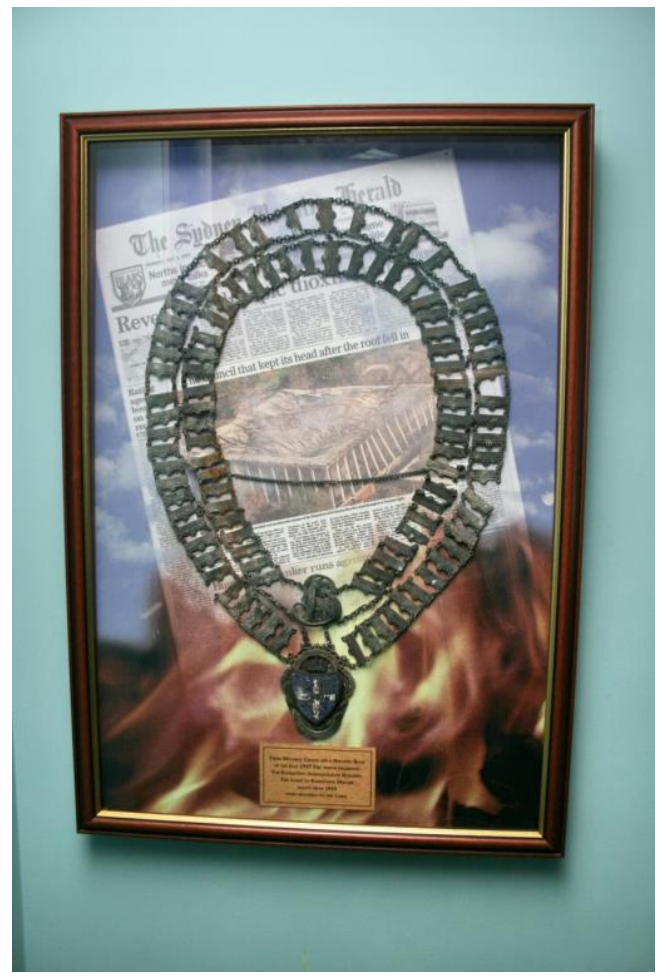

Figure 1: The charcoaled mayoral chain

Yet amid what we later go on to describe as positive accounts of change, the impact of both the restructure and the fire meant that some workers found the latter event more difficult to cope with. The following is from a worker who had been with Council for over 30 years at the time of interviewing:

The building burnt down and then - we already had this building [Council's existing premises], and so The Council moved, partly ... to here [current premises] - and we were spread all over the place, so it was chaos at the time. At one time we were in the $X$ building [a few streets away] near Jelally Street - and that was a big shock. A lot of 
people were really - I must say, I was really shocked - and I think I - shocked with the fire, shocked with the structure of The Council, shocked in the direction The Council was going - this guy [the General Manager] was nothing more than a used car salesman, in my opinion.

Despite the above example, the discourse of workers was predominantly and overwhelmingly positive. Most saw the fire as an event that spurred people on to new ways of relating and doing. Among these was a manager who described change in terms of 'challenges', 'excitement' and 'learning':

Can I tell you that the fire was actually a positive thing because all of - I mean there was a lot of residual angst-but back in '97 I mean [the restructure] was still fresh, it was only two years after the change and the fire and what I noticed was that a lot of the staff who were - I call 'the cardigan brigade' - who were apathetic about the change, and some of the management, pulled their socks up, got in, it was an extraordinarily difficult time.

Repeatedly we heard how important the fire had been in reconstructing the organizational culture of PCC. Many thought the fire was advantageous for The Council because it drew people together', thus having a deep social impact on working relations. Meanwhile, others noted different yet still positive outcomes of the fire: 'sure in a fire we have lots of valuable things lost but if ever an organization needed a clean out, [this was it!]'. In this latter quote the fire completed the work of the earlier restructure, as another worker suggested:

Well, I mean, [the fire's] a perfect example of how we had gone from ... I guess, the 'them' and 'us' syndrome of local government [to a more unified notion of togetherness].

To conclude these PCC stories of major changes, we include a comment from a worker who notes that:

At the end of that fire crisis, the buzz had gone back to the ordinariness ... so you can imagine all those subtle changes have now happened, and again, another great period of stability, almost of getting too boring.

However, this 'ordinariness' did not last long. The purchaser-provider split was embedded and again dismantled. At the time of writing, PCC is in the process of amalgamating with 
another Local Council in line with the more recent New South Wales Government reforms of 'Fit for the Future'. The existing PCC General Manager has been appointed as the interim General Manager of the new amalgamated Council and an external Administrator has been appointed until a new Council is to be elected in 2017. We can only postulate on how this major change will unfold for PCC and its workers. The focus of the paper remains on the 'fire stories', although we suspect that its legacy has embedded affective practices of resilience, commitment and a capacity to 'pull-through' adversity, ways of doing and relating that now reside in the 'practice memory' of the organization.

\section{THE ENTANGLEMENT OF MATERIALITY, AFFECT AND LEARNING}

It is the stories told by PCC workers that we have drawn on above to tell our own first research story. However, the telling of that research account invites yet another. This section refocuses analytically by (re)presenting the fire stories in terms of 'materiality', 'affect' and 'learning' and illustrates their entanglement. We offer this emergent research account in order 'to entertain', 'to teach' and 'to learn'.

Our argument is that the material event of the fire precipitated a collective affective response resulting in change, and implicitly, learning. We propose that workers had been significantly affected by the fire (and the organization's earlier restructure) and this meant that change and learning were not only possible, but were likely. We argue this likelihood because a dramatic shift occurred in the workers and this was a direct response to how they were affected by the fire. The workers' stories constructed affective dimensions of organizational change which we examine through a practice-based lens drawing on our data to show how these implicated learning.

Our second layer of analysis thus brings together practice conceptualisations (Gherardi 2017) which we draw on to explore the entangled materiality (including temporal materialities) of the fire and how this affected workers organizationally. Gherardi proposes that affect is a 'collective' phenomenon allowing us to analyse how The Council workers responded to social and material aspects of the world corporeally, through their bodies, redefining relations, through contagion. This is because ' $[\mathrm{t}]$ he body is the interface with the 
world, and it is what we learn to use to become sensitive to the world' (Gherardi 2017, p. $355)$.

Gherardi (2017), drawing on Wetherell (2015), explains how affect might be understood from a practice-based perspective:

A practice approach positions affect as a dynamic process, emergent from a polyphony of intersections and feedbacks, working across body states, registrations and categorizations, entangled with cultural meaning-making, and integrated with material and natural processes, social situations and social relationships' (Wetherell 2015, p. 139, in Gherardi 2017, p. 349).

According to Gherardi, Wetherell argues that 'a notion of affective practice is more commensurate with trends in contemporary psychobiology, since it emphasizes relationality and negotiation, and is attentive to the flow of affecting episodes' (Gherardi 2017, p. 349). The relationships between workers and the fire - the 'affecting episode' were entangled with each other - workers weren't just individually experiencing what had occurred, they were relating differently collectively; they were doing things differently; they were learning and changing; driven in a way as much by their habits as their impulses.

Gherardi identifies the interplay between these seemingly contradictory elements (habits and impulses) outlining that this is precisely how affect implicates 'a movement between the voluntary and the involuntary' (Gherardi 2017, p. 355). Workers, now affected, shifted their mundane actions from the ordinary to the reconfigured, wherein we argue, learning new practices resided. This phenomenon had been similarly recognised long ago as implicating practice 'change' by Dewey himself:

Impulses are the pivots upon which the reorganization of activities turn, they are the agencies of deviation, for giving new directions to old habits [ordinariness] and changing their quality (Dewey 1922, p. 104).

The fire immediately altered the space and material arrangement of work practices and ways in which the workers related to these. The 'material arrangements' (Schatzki 2005) of work practices were changed: 
The day after the fire, everyone came in, the morning of the fire, and we told them that they could [ ] all go home and we'd be ready for them on Monday. To the best of our knowledge nobody went home, we had people filling out DAs ${ }^{3}$ on the boot of their car, in the car park. By ten o'clock we had the phones on, we had temporary buildings down in that car park. By midday we were up and running, and this five story building was just smouldering in the background, but we know of nobody that went home.

New work practices resulted in new ways of enacting work practices and new ways of workers' relating to each other:

You can't just imagine what you do when you can't get into your building and you've 'gotta' run a $\$ 110$ million business; you know from demountables ${ }^{4}$ and mobile 'phones and borrowed furniture. But the staff actually picked up and I think the fire in many ways sort of aided the healing of the dislocation and disaffection of some staff from the structural change in '95.

One worker used the metaphor of the phoenix in his story of Council's fire. While not necessarily setting itself alight, PCC literally burned and arose from the ashes anew:

Out of the fire for me the so-called phoenix rising was an opportunity - because it coincided with [the establishment of the purchaser-provider split and the Civic Services Group] - we [Civic Services Group] were going to conquer the world - to be honest we couldn't really give a stuff about the Town Hall'.

What the worker expresses is an affective, dynamic response to the material event, dismissing both the tragedy of the fire and the building it destroyed - as he articulates a sense of strength and power 'we were going to conquer the world'.

\footnotetext{
${ }^{3}$ Development Applications for new construction projects

4 Temporary buildings

5 The Head Office of The Council
} 
In addition to salvaged material artefacts such as the charcoaled mayoral chain (seen in Figure 1 above) new artefacts such as the 'Operation Phoenix' Coffee mugs emerged (see Figures $2 \& 3$ below). These mugs were given to all staff as material reminders that they 'survived' the fire and were working to 'raise PCC from the ashes'.

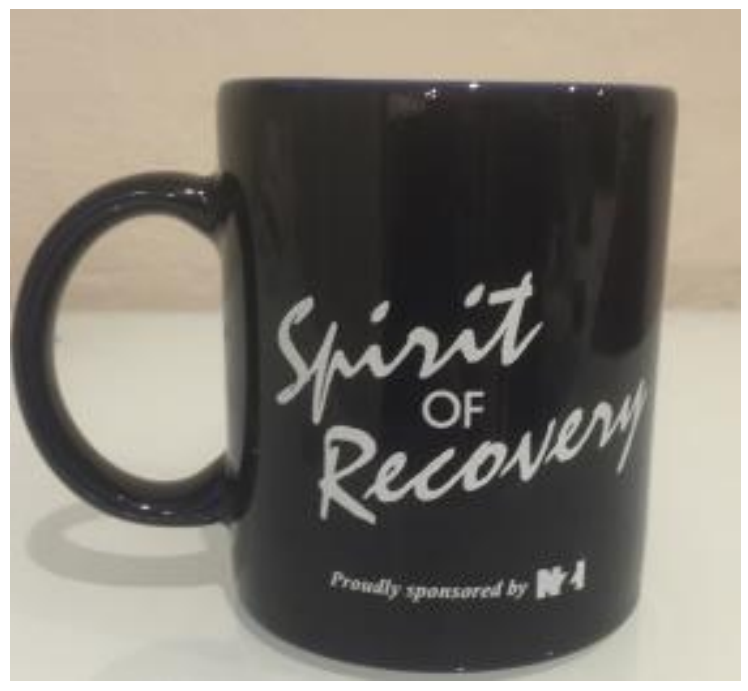

Figure 2 'Operation Phoenix' Mug - the past, present and future

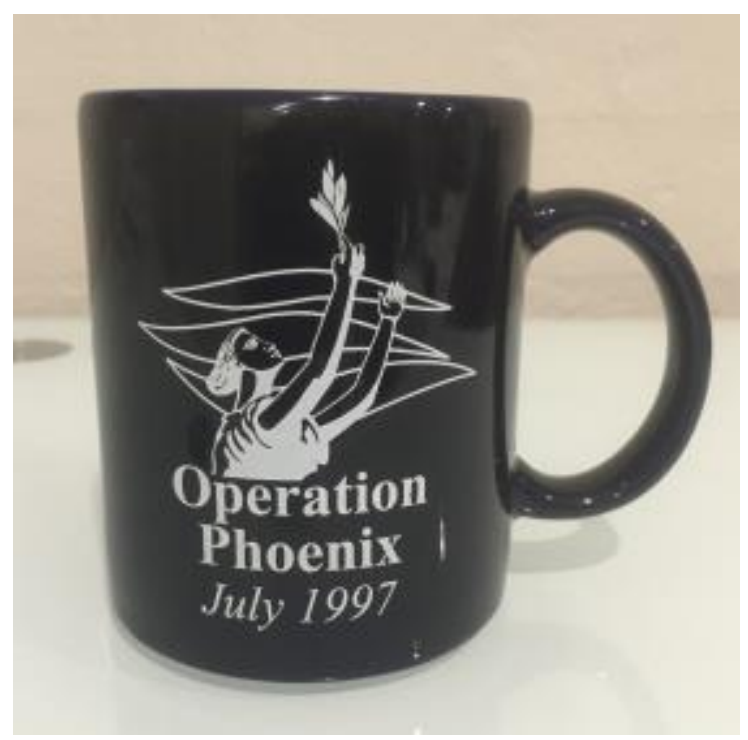

Figure 3 'Operation Phoenix' Mug - the past, present and future

We focus on The Operation Phoenix mug as both a material as well as a symbolic artefact linking the past of The Council to its present and taking it into the future. In this latter incarnation, it fits with the 'Fit for the Future' blueprint of new Council amalgamations. In 
addition, the mug's message is directly affectual in its wording and the phrase 'spirit of recovery' suggesting invisible but nevertheless human triumph, healing and endeavour. The mug's other message 'Operation Phoenix' suggests work and production of some kind. In its diagrammatic representation, the logo of the waves was The Council's original emblem and the image of the woman holding a new leaf with her arms uplifted also invokes hope, and new growth.

Symbolically and materially, the mugs established a link to the eponymous mythical bird that appears as a symbol of resurrection and rebirth: renewed and ready for succession. The bird is known for its paradoxically melodious dirge and, when not engaged in fire starting, is said to be flying:

[A]lways scanning the landscape and distant space. It represents our capacity for vision, for collecting sensory information about [the] environment and the events unfolding within it. The phoenix, with its great beauty, creates intense excitement and deathless inspiration (Kam-Chuen 1996:n.p).

The existence of the artefactual mug materialised one aspect of The Council's 'timespace' a notion conceptualised by Schatzki (2010b). This concept recognises any endeavour in its unfolding as taking place in connected 'timespaces'. The Council 'as it happens' (Schatzki 2006) operates in a simultaneous past, present and future as a site made up of practices and material arrangements. Not only does the mug provide a material link to the history of The Council, its present and its future, but the continuum of time is noted in the practices as well, some of which were resurrected from the past into the present, after the fire. For example, the fire precipitated a return to previously learned practices from earlier days of PCC, practices which had been superseded by more recent and more modern technologies. So, workers returned to manual practices for receipting, managing of customer complaints, looking up of rates and details on microfiche and also the use of manual accounting processes.

The major event of the fire recounted by workers is an example of the affective response in which workers saw both opportunity and renewal for the organization and for their practices. A new organization and new practices emerged through an entanglement of materialities, affect and learning. New materialities and practices generated a revitalised 
order embodied in the way all council workers (re)engaged through collective practice. Workers were open to emergent collective learning that was 'extra-individual' (Kemmis 2009) through unrehearsed (impulsive) practices as they sought to regain a kind of social and organizational order after the fire. This connects to our understanding of learning, focusing on individuals participating in collective practices as these unfolded in situ. Learning has been understood as emergent as workers reflected and responded to the sociomaterial exigencies in this particular work context as these shifted and changed. What many workers had been doing before the fire - bordering on boring ordinariness as noted above - was changed inexorably and suddenly.

\section{CONCLUDING COMMENTS}

The organizational stories gathered as part of our initial narrative enquiry featured individual and organizational change and centred around the fire story. The fire story itself was told as a kind of regeneration or even re-birthing of the organization with attendant excitements and challenges, and ways this impacted individually, collectively and organizationally. The changes experienced individually and collectively in situ to workers, team members and to Council itself, we argue, reflect the entanglement of materiality, affect and learning.

Change (and learning) were implicit in keeping the PCC going, a shift that we were observing and recording in our interviews, through individual and collective 'practical intelligibility' as workers did what made sense to them to do in the circumstances (Schatzki 1996). After the fire, workers resorted to earlier practices, invented new ones opening up the practice 'space' embracing (affectively) different doings, sayings and relatings. While we acknowledge that the idea of materiality is not always theoretically agreed on, our understanding of it is deliberately broad. Conceptualising the fire as a significant 'material' event along with the other more conventional dimensions of materiality including time and space, bodies, things and artefacts (Fenwick 2010; Hopwood 2016; Schatzki 2010a), has enabled us to explore how The Council, organizational teams and individual workers learned to adapt, change and relate in new ways. 
This paper is as much about the emergent nature or work and organizations as it is about the reflexive and emergent nature of research itself. As in the nature of much qualitative research we have used conceptual lenses of narrative and practice to understand our participants' (workers') stories of their workplaces. We did so in an effort to construct our own research story about learning and change. Ironically, that story led us (and the paper) to another related account where the lenses of materiality and affect emerged which contribute further to our account of learning and change.

The Council's restructure and the fire shared a similar narrative. Each told a story where the actors (The Council as a whole, teams or individual workers) were 'thrown into the deep end' - a crisis - and emerged as something/somebody new and perhaps better. The consequences of a crisis - affect - necessitated changes that provided conditions for learning. Just as the organization was undergoing renewal and becoming an enterprising organization, so too the workers were constructing themselves as enterprising subjects du Gay 1996). New ways of seeing themselves and the organization were precipitated by a significant material change, their reactions to it and their learning from it. Materiality, affect and learning were 'entangled', establishing new workers, new practices and a new organization. Like the Phoenix, workers, and the organization reported on here, 'arose' from the crisis and changed as new workers and as a new organization.

Likewise, we as researchers have undergone change ourselves (admittedly less dramatic than the workers) over the duration of our involvement in this research. What started out as an effort to provide a research story of change and learning has emerged into new ways of seeing, doing and relating to ideas of change and learning. Our own 'enterprising (research) selves' have changed through the retelling. Narratives do indeed provide an opportunity 'to entertain, to teach and to learn' (Czarniawska 2004, p. 10).

\section{REFERENCES}

Al-Haddad, S. \& Kotnour, T. 2015, 'Integrating the oorganizational change literature: a model for successful change', Journal of Organizational Change Management, vol. 28, no. 2, pp. 234-62.

ANON 2013. 
ANON 2009.

ANON 2011

Billett, S. 2004, 'Workplace participatory practices: conceptualising workplaces as learning environments', The Journal of Workplace Learning, vol. 16, no. 6, pp. 312-24.

Brunsson, N. \& Sahlin-Andersson, S. 2000, 'Constructing organizations: the example of public sector reform', Organization Studies, vol. 21, no. 4, pp. 721-46.

Czarniawska, B. 2004, Narratives in social research, Sage, London.

Dewey, J. 1922, Human nature and conduct: an introduction to social psychology, Henry Holt and Company, New York.

du Gay, P. 1996, Consumption and identity at work, Sage, London

Fenwick, T.J. 2010, 'Re-thinking the thing: sociomaterial approaches to understanding and researching learning at work', Journal of Workplace Learning, vol. 22, no. 1, pp. 104-16.

Fenwick, T.J. 2016, Professional responsibility and professionalism: a sociomaterial examination, Routledge, Milton Park, Abingdom, Oxon.

Gherardi, S. 2008a, 'Situated knowledge and situated action.', in D. Barry \& H. Hansen (eds), The SAGE handbook of new approaches in management and organization, SAGE Publications Ltd, London, pp. 516-25.

Gherardi, S. 2008b, 'Situated Knowledge and Situated Action: What do Practice-Based Studies Promise?', in D. Barry \& H. Hansen (eds), The SAGE Handbook of New Approaches in Management and Organization, Sage, Los Angeles, pp. 516-25.

Gherardi, S. 2015, 'To start practice-theorizing anew: the contribution of the concepts of agencement and formativeness', Organization, pp. 1-19.

Gherardi, S. 2017, 'One turn ... and now another one: Do the turn to practice and the turn to affect have something in common?', Management Learning, vol. 48, no. 3, pp. 34558 .

Gherardi, S., Nicolini, D. \& Odella, F. 1998, 'Toward a social understanding of how people learn in organizations', Management Learning, vol. 29, no. 3, pp. 273-97.

Hager, P. 2011, 'Theories of workplace learning', in M. Malloch, L. Cairns, K. Evans \& B. O'Connor (Eds), The SAGE Handbook of Workplace Learning, SAGE Publications, London, pp. 17-31.

Hager, P. 2014, 'Practice as a key idea in understanding work-based learning', in P. Gibbs (ed.), Learning, work and practice: new understandings, Springer, Dordrecht, pp. 85-106.

Hopwood, N. 2016, 'Professional Practice and Learning Times, Spaces, Bodies, Things', Springer International Publishing, Switzerland. 
Kam-Chuen, L. 1996, The feng shui handbook: How to create a healthier living and working environment, Henry Holt Reference Book, Gala Books Limited. London. Available at http://www.onmarkproductions.com/html/phoenix-china-popup.html [accessed 27 November 2017]

Kemmis, S. 2009, 'Understanding Professional Practice: A Synoptic Framework', in B. Green (ed.), Understanding and Research Professional Practice, Sense Publishers, Rotterdam, pp. 19-38.

Lave, J. \& Wenger, E. 1991, Situated learning: legitimate peripheral participation, Cambridge University Press, Cambridge.

Schatzki, T.R. 1996, Social practices:A Wittgensteinian approach to human activity and the social, Cambridge University Press, Cambridge.

Schatzki, T.R. 2002, The site of the social: a philosophical account of the constitution of social life and change, Pennsylvania State University Press, Pennsylvania. Schatzki, T.R. 2010, 'Materiality and Social Life', Nature and Culture, vol. 5, no. 2, pp. 123 49.

Schatzki, T.R. 2005, 'Peripheral vision: The sites of organizations', Organization Studies, vol. 26, no. 3, pp. 465 - 84 .

Schatzki, T.R. 2006, 'On organizations as they happen', Organization Studies, vol. 27, no. 12, pp. 1863-73.

Schatzki, T.R. 2010a, 'Materiality and Social Life', Nature and Culture, vol. 5, no. 2, pp. 123-49.

Schatzki, T.R. 2010b, The timespace of human activity: On performance, society and history, Lexington, Lanham, MD.

Wetherell, M. 2015, 'Trends in the turn to affect: A social psychological critique', Body and Society, vol. 21, no. 2, pp. 139-66. 